\title{
Zerumbone attenuates lipopolysaccharide-induced activation of BV-2 microglial cells via NF-KB signaling
}

Min Ji Gu${ }^{1 \dagger}$, Pyeongjae Lee ${ }^{2}$, Sang Keun $\mathrm{Ha}^{1{ }^{*+}}$ and Jinyoung Hur ${ }^{1{ }^{*+}}$ (C)

\begin{abstract}
The brain is considered an immune-privileged organ. However, it has been found that inflammation mediated by microglia, which were once believed to support the brain structure, plays important roles in neuronal cell survival and death. Whether activated microglia has beneficial or detrimental effects on neurons remain controversial. Activated microglia could contribute to maintaining homeostasis in the brain by removing damaged cells. Nonetheless, dysregulation of microglial activation leads to neuronal cell death. Therefore, much attention has been paid to compounds that regulate microglial activation. Zerumbone, a constituent of Zingiber zerumbet, has been reported to exert several biological activities such as anticancer, anti-bacterial, and anti-inflammatory effects. In this study, we aimed to determine the anti-inflammatory effect of zerumbone on lipopolysaccharide-induced activation of BV-2 microglial cells and elucidate the underlying mechanism of action. Zerumbone suppressed nitric oxide and prostaglandin $\mathrm{E}_{2}$ production induced by lipopolysaccharides through inhibiting the expression of inducible nitric oxide synthase and cyclooxygenase-2. Blocking of mitogen-activated protein kinase and NF-KB activation, if not completely, is considered to be due to the anti-inflammatory effect of zerumbone against microglial activation.
\end{abstract}

Keywords: Zerumbone, Microglia, BV-2, Neuroinflammation, Anti-inflammation, NF-KB

\section{Introduction}

Microglia are macrophage-like cells in the brain that constitute the microenvironment necessary for synapse formation and normal functioning of neurons; they protect normal neurons by removing nearby apoptotic cells [1-4]. Two types of microglial activation are necessary for apoptotic cell removal: M1 and M2. M1 microglia produce nitric oxide (NO) and pro-inflammatory cytokines, such as tumor necrosis factor- $\alpha$ (TNF- $\alpha$ ) and interleukin-1 $\beta$ (IL-1 $\beta)$, to mediate inflammatory responses. M2 microglia produce anti-inflammatory cytokines to inhibit excessive neuronal apoptosis [5].

\footnotetext{
*Correspondence: skha@kfri.re.kr; jyhur@kfri.re.kr

${ }^{\dagger}$ Min Ji Gu, Pyeongjae Sang Keun Ha and Jinyoung Hur contributed equally to this work

${ }^{1}$ Korea Food Research Institute, 245, Nongsaengmyeong-ro,

Jeollabukdo 55365, Republic of Korea

Full list of author information is available at the end of the article
}

Inflammatory responses, which must be carefully controlled, can result from an overabundance of microglia and damage the surrounding normal cells eventually, consequently causing or aggravating a neurologic disorder. Studies have reported that long-term microglial activation contributes to the development and exacerbation of degenerative brain diseases such as Alzheimer's disease, Parkinson's disease, and stroke [6-8]. It has also been reported that natural substances that control microgliamediated inflammatory responses are effective against degenerative brain diseases [9-11]. Zerumbone (Fig. 1a) is a sesquiterpene compound extracted from the rhizomes of Zingiber zerumbet, a plant species in the ginger family grown in the tropical regions of Southwest Asia; several bioactivities of zerumbone have been reported $[12,13]$. It is known to exert anticancer effects in various cancer cells by inhibiting NF- $\mathrm{KB}$ activation and regulating the expression of inflammation-related genes, including 
<smiles>CC=CC(=O)C(C)=CCC(C)(C)C=CC(C)=CCC</smiles>

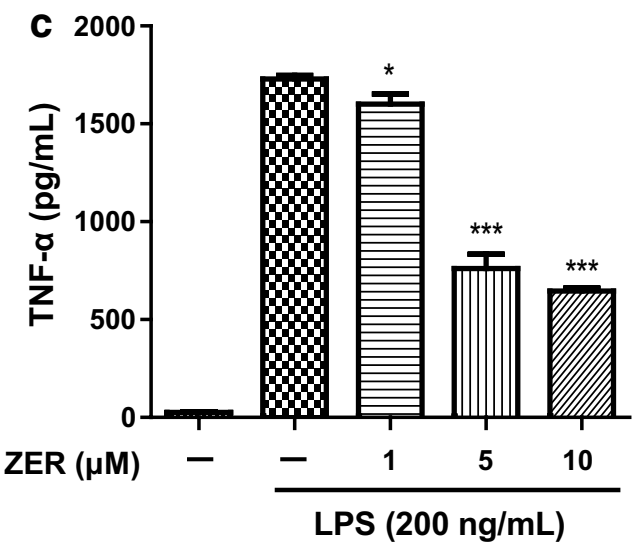

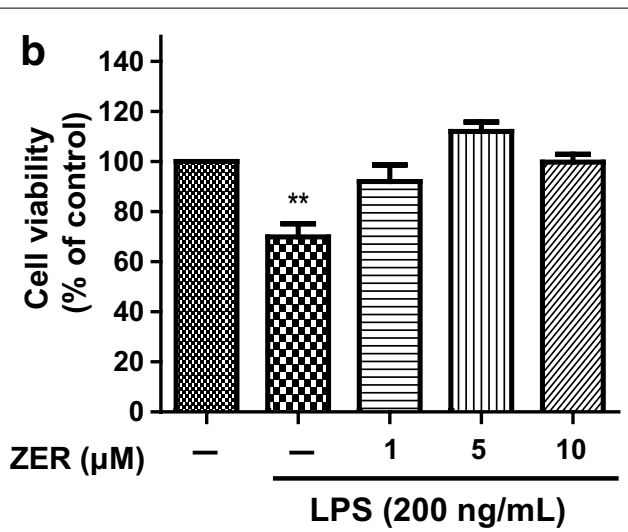

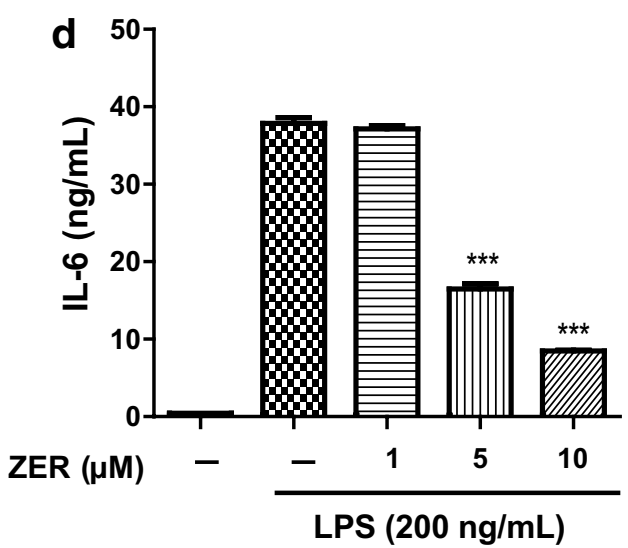

Fig. 1 Chemical structure of zerumbone (a) and effect of zerumbone $(1,5,10 \mu \mathrm{M})$ on viability of LPS (200 ng/mL)-treated BV-2 cells (b). Inhibitory effect of zerumbone $(1,5,10 \mu \mathrm{M})$ on TNF-a and IL- 6 levels in LPS-stimulated BV-2 cells

interleukin-6 (IL-6) and cyclooxygenase-2 (COX-2) [14, 15]. A previous study reported that zerumbone inhibits inflammation-induced cancer cell proliferation by inhibiting TNF- $\alpha$ activation [16]. The anticancer effect of $Z$. zerumbet extract and zerumbone has been reported in many studies. Z. zerumbet extract and zerumbone inhibited the phosphorylation of mitogen-activated protein kinases (MAPK), Akt, and inhibitory-kappa $B \alpha(\mathrm{I} \kappa \mathrm{B} \alpha)$ in lipopolysaccharide (LPS)-activated U937 macrophages, thereby inhibiting the production of pro-inflammatory cytokines (TNF- $\alpha, \mathrm{IL}-1 \beta)$ and prostaglandin $\mathrm{E}_{2}\left(\mathrm{PGE}_{2}\right)$ $[17,18]$. Zerumbone inhibited the production of $\mathrm{NO}$ and $\mathrm{PGE}_{2}$ in LPS-stimulated Raw 264.7 cells, a macrophage cell line [19]. In addition, it inhibited the production of NO, PGE ${ }_{2}$, TNF- $\alpha$, and IL- 6 by inhibiting Akt-NF- $\mathrm{BB}$ activation in LPS-induced acute injuries [20]. Moreover, macrophage infiltration and pro-inflammatory cytokine production in hyperglycemia-treated kidneys were inhibited by zerumbone [21]. Furthermore, it inhibited acetylcholinesterase activity and reduced memory deficits in scopolamine-treated animal models of dementia [22, 23]. Based on previous reports on the neuroprotective and anti-inflammatory effects of zerumbone, we hypothesized that zerumbone can sufficiently inhibit microglial activation and provide neuroprotection. Thus, we aimed to investigate the anti-inflammatory effect and mechanism of action of zerumbone in BV-2 microglia.

\section{Materials and methods \\ Materials}

Dulbecco's modified Eagle medium (DMEM), fetal bovine serum (FBS), and penicillin-streptomycin (PS) were purchased from Gibco (Grand Island, NY, USA). LPS, Griess reagent, zerumbone [(2E,6E,10E)-2,6,9,9tetramethylcycloundeca-2,6,10-trien-1-one], and 3-(4,5-dimethyl-2-thiazolyl)-2,5-diphenyl tetrazolium bromide (MTT) powder were acquired from Sigma Chemical Company (St. Louis, MO, USA). The nuclear/ cytosol extraction kit was purchased from BioVision (San Francisco, CA, USA). Primary antibodies against Cox-2, iNOS, ІкB, NF-кB, p38, phospho-p38 (Thr180/Tyr182), ERK, phospho-ERK (Thr202/Tyr204), JNK, and phospho-JNK (Thr183/Tyr185) were obtained from Cell Signaling (Beverley, MA, USA). Anti-rabbit IgG horseradish 
peroxidase (HRP)-conjugated secondary antibody was obtained from Invitrogen (Carlsbad, CA, USA).

\section{Cell culture}

The immortalized murine microglial BV-2 cell line was generously provided by Dr. Myungsook Oh from Kyunghee University (Seoul, Korea). BV-2 microglial cells were cultured in DMEM supplemented with heat-inactivated $10 \% \mathrm{FBS}$ and $1 \% \mathrm{PS}$ and maintained in a humidified incubator containing $5 \% \mathrm{CO}_{2}$ and $37^{\circ} \mathrm{C}$.

\section{NO assay and cell viability}

BV-2 cells were seeded in 96-well plates and treated with various concentrations of zerumbone in the presence or absence of LPS (200 ng/mL). Following LPS stimulation, $50 \mu \mathrm{L}$ culture media from each plate was mixed with an equal amount of Griess reagent. The absorbance of nitrite $\left(\mathrm{NO}_{2}{ }^{-}\right)$was measured at $540 \mathrm{~nm}$ using a microplate reader. Nitrite concentration was calculated from the standard curve of $\mathrm{NaNO}_{2}$. Cell viability was assessed using MTT assay. The absorbance at $570 \mathrm{~nm}$ was detected using a microplate reader (SpectraMax M5, Molecular Devices, Sunnyvale, CA, USA). Cell viability was expressed as a percentage of the untreated control.

\section{Cell lysis and nuclear protein extraction}

To evaluate the expression of MAPKs and NF- $k B, B V-2$ cells were treated with various concentrations of zerumbone in the presence or absence of LPS $(200 \mathrm{ng} / \mathrm{mL})$. The cells were prepared by centrifugation at $16,000 \times g$ for $5 \mathrm{~min}$ at $4{ }^{\circ} \mathrm{C}$, and the pellets were lysed with protein extraction solution (iNtRON Biotech, Burlington, USA). Nuclear and cytosol fractions from treated BV-2 cells were extracted using nuclear/cytosol extraction kit.

\section{Effect of Zerombone on MAPK signaling inflammatory proteins}

The cell extracts were quantified using Bradford assay kit (Bio-Rad Lab, Hercules, CA, USA), and the protein concentration was determined using bovine serum albumin as the standard. The protein samples were separated on $10 \%$ sodium dodecyl sulfate-polyacrylamide gel electrophoresis (SDS-PAGE) and transferred to a nitrocellulose membrane (Bio-Rad Lab). The membranes were blocked with $5 \%$ skim milk in tris-buffered saline containing $0.2 \%$ Tween-20 (TBST) for $1 \mathrm{~h}$ at room temperature and then incubated overnight with primary antibodies against iNOS, COX-2, p38, ERK, JNK, phospho-p38, phosphoERK, phospho-JNK, IкB, and NF-кB at $4{ }^{\circ} \mathrm{C}$. The membranes were incubated with $5 \%$ skim-milk in TBST at room temperature for $1 \mathrm{~h}$ with secondary antibodies conjugated to HRP. The protein blots were visualized using Lumi Pico solution (Dogen Bio, Seoul, Korea). Each band was quantitatively determined using Image Lab software (NIH, Bethesda, MD, USA). In each experiment, the density ratio represented the relative intensity of each band against that of $\beta$-actin or lamin B1 as a control.

\section{Effect of zerombone on pro-inflammatory cytokines}

BV-2 cells were plated at a density of $5.0 \times 10^{4}$ cells/well in a 96-well culture plate. The cells were treated with zerumbone $(1,5$, and $10 \mu \mathrm{M})$ and stimulated with LPS $(200 \mathrm{ng} / \mathrm{mL})$ for $24 \mathrm{~h}$. Then, the cell culture media were

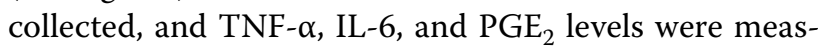
ured using ELISA kits for TNF- $\alpha$, IL- 6 (R\&D system, Minneapolis, USA), and PGE $_{2}$ (ENZO Life Sciences, NY,

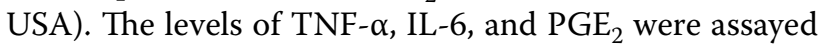
according to the manufacturer's instructions.

\section{Statistical analysis}

The data were analyzed using Statistical Analysis System software (GraphPad Prism 5, GraphPad Software Inc., CA, USA). At least three independent experiments were performed for each experiment. All the data are expressed as mean \pm S.E.M. Statistical comparisons between the different treatments were performed using one-way ANOVA with Tukey's multiple comparison post hoc test. The values of ${ }^{*} p<0.05,{ }^{* *} p<0.01$, and ${ }^{* * * *} p<0.001$ were considered statistically significant.

\section{Results}

\section{Zerumbone inhibits LPS-induced pro-inflammatory} reaction in BV-2 cells

The viability of BV-2 cells treated with $200 \mathrm{ng} / \mathrm{mL}$ LPS alone was $75 \%$ of that of the control group, indicating a significant increase in cell death following LPS treatment. However, no significant difference in viability was observed between BV-2 cells treated with LPS in addition to 1,5 , or $10 \mu \mathrm{M}$ zerumbone and the control group. Thus, it was assumed that any LPS- or zerumbone-induced changes in the amount of protein production in BV-2 cells would not be the result of cell death and proliferation (Fig. 1b). The levels of pro-inflammatory cytokines TNF- $\alpha$ and IL- 6 in BV-2 cell culture media increased to $1738 \mathrm{pg} / \mathrm{mL}$ and $37 \mathrm{ng} / \mathrm{mL}$, respectively, following treatment with LPS alone. In contrast, treatment with $1 \mu \mathrm{M}$ zerumbone did not significantly reduce TNF- $\alpha$ level. Treatment with 5 and $10 \mu \mathrm{M}$ zerumbone reduced TNF- $\alpha$ levels to 772.1 and $643.8 \mathrm{pg} / \mathrm{mL}$, respectively, indicating a dose-dependent reduction in TNF- $\alpha$ production by over $50 \%$ (Fig. 1c). Treatment with $1 \mu \mathrm{M}$ zerumbone did not affect IL- 6 production, but treatment with 5 and $10 \mu \mathrm{M}$ zerumbone reduced IL-6 levels to 16.8 and $8.6 \mathrm{ng} / \mathrm{mL}$, respectively. Treatment with $10 \mu \mathrm{M}$ zerumbone reduced IL-6 production by over $78 \%$ (Fig. 1d). 
Zerumbone suppresses iNOS and COX-2 protein expression The level of NO was $66.8,33.4$, and $10.2 \%$ in the groups treated with 1,5 , and $10 \mu \mathrm{M}$ zerumbone, respectively, relative to that in LPS-treated group, indicating a dosedependent suppression of NO production by LPS
(Fig. 2a). The level of $\mathrm{PGE}_{2}$ was $46.5 \mathrm{pg} / \mathrm{mL}$ in the control group and $78.6 \mathrm{pg} / \mathrm{mL}$ in the LPS-treated group, indicating that LPS treatment increased $\mathrm{PGE}_{2}$ production by approximately twofold. Treatment with 1,5 , and $10 \mu \mathrm{M}$ zerumbone resulted in $\mathrm{PGE}_{2}$ levels of $71.3,45.8$, and
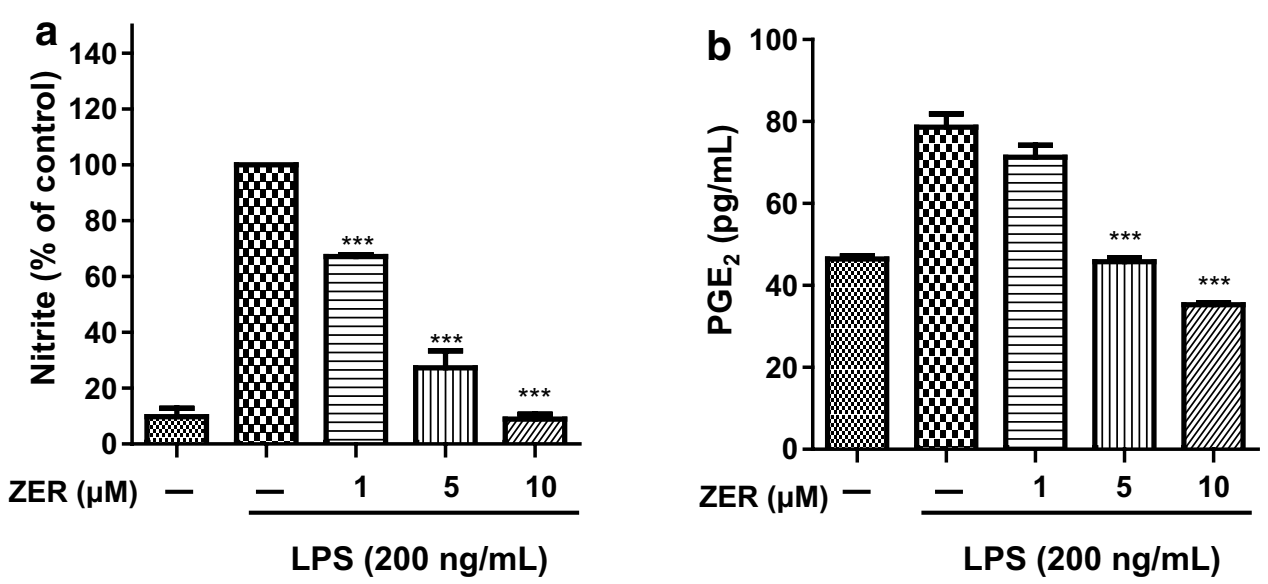

C LPS $(200 \mathrm{ng} / \mathrm{mL})$
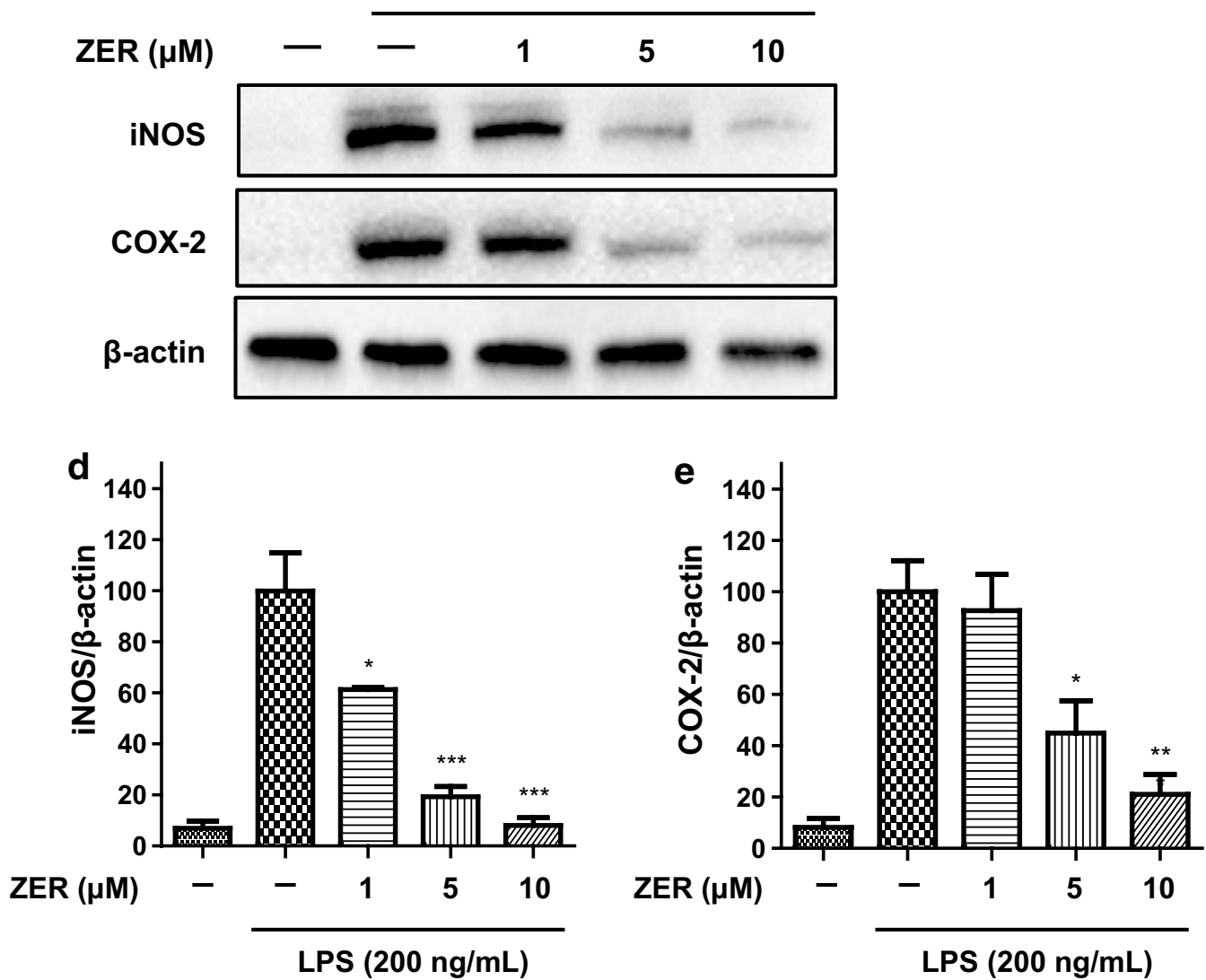

Fig. 2 Inhibitory effect of zerumbone (1, 5, $10 \mu \mathrm{M})$ on $\mathrm{NO}$ and PGE 2 production in LPS-stimulated BV-2 cells (a, b). Suppressive effect of zerumbone $(1,5,10 \mu \mathrm{M})$ on iNOS and COX-2 protein expression induced by LPS in BV-2 cells (c). Normalization of iNOS and COX-2 protein band intensity to that of $\beta$-actin $(\mathbf{d}, \mathbf{e})$ 
$35.3 \mathrm{pg} / \mathrm{mL}$, respectively; 5 and $10 \mu \mathrm{M}$ zerumbone inhibited $\mathrm{PGE}_{2}$ production (Fig. 2b). The production of $\mathrm{NO}$ and $\mathrm{PGE}_{2}$ in $\mathrm{BV}-2$ cells resulted from an LPS-induced increase in inducible nitric oxide synthase (iNOS) and cyclooxygenase-2 (COX-2) levels. In this study, zerumbone markedly reduced the levels of iNOS and COX-2 expression elevated by LPS (Fig. 2c). Treatment with LPS alone increased the levels of iNOS and COX-2 expression by approximately 10.8 - and 15 -fold, respectively, relative to the expression levels in the control group. Treatment with 1,5 , and $10 \mu \mathrm{M}$ zerumbone reduced the expression level of iNOS in a dose-dependent manner to $30,25.1$, and $11 \%$, respectively, relative to the expression level in the control group (Fig. 2d). Treatment with 5 and $10 \mu \mathrm{M}$ led to a marked reduction in the level of COX-2 expression, whereas treatment with $1 \mu \mathrm{M}$ zerumbone did not significantly reduce COX-2 expression (Fig. 2e). This could be a possible reason why $\mathrm{PGE}_{2}$ level was not significantly reduced in cells treated with $1 \mu \mathrm{M}$ zerumbone compared with that in LPS-treated cells.

\section{Zerumbone inhibits the phosphorylation of p38 and JNK but not of ERK}

The level of phosphorylated MAPK was measured to investigate how zerumbone affects MAPK, which was activated by LPS. Phosphorylation of p38 and JNK was observed following treatment with LPS alone. In addition, LPS treatment increased ERK phosphorylation but not significantly. Zerumbone did not affect ERK phosphorylation (Fig. 3a, d). Following treatment with $10 \mu \mathrm{M}$

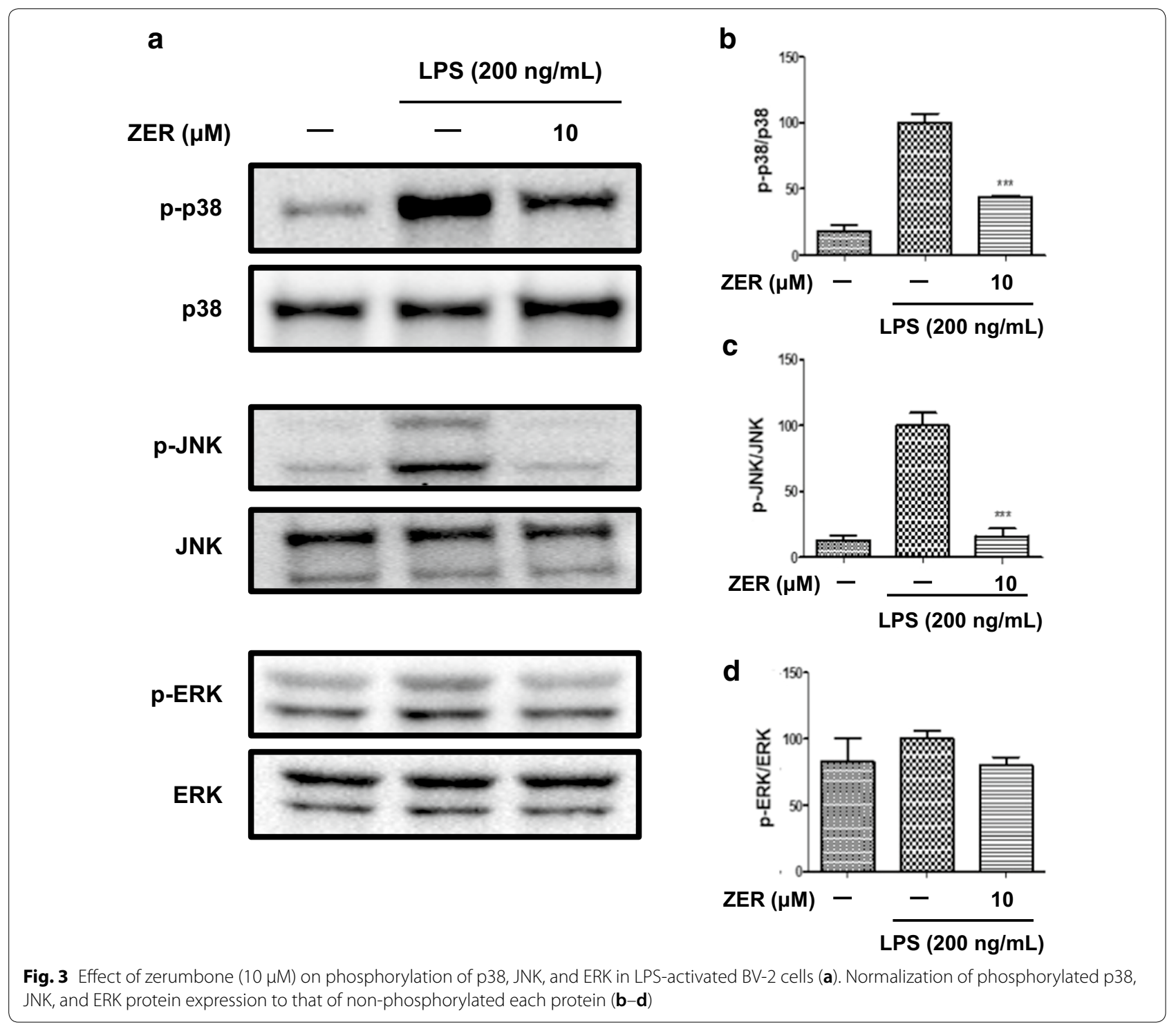


zerumbone, the expression level of p38 was $46.9 \%$, which indicated an approximately $50 \%$ reduction in phosphorylation level compared with the LPS-treated group. The level of JNK expression following zerumbone treatment was $14 \%$, and it did not significantly differ from the level of JNK expression in the control group (Fig. 3b, c). Based on these results, we suggest that zerumbone inhibited LPS-induced phosphorylation of JNK more significantly than it inhibited LPS-induced phosphorylation of other proteins.

\section{Zerumbone suppresses the translocation of NF-кB from cytosol to the nucleus}

$\mathrm{NF}-\mathrm{kB}$, which affects the expression of proinflammatory genes iNOS and COX-2, is bound to I $\mathrm{KB}$ in the cytosol and cannot translocate to the nucleus unless stimulated by LPS. Following treatment with LPS, IKB is phosphorylated and separates from NF- $\kappa B$, allowing free NF- $\mathrm{KB}$ to translocate to the nucleus. The phosphorylated ІкB is eventually degraded. To determine whether suppressing the expression of anti-inflammatory genes inhibits the translocation of $\mathrm{NK}-\mathrm{KB}$ to the nucleus, we examined the presence of $\mathrm{I} \kappa \mathrm{B}$ and NF- $\mathrm{KB}$ components in the cytosol and nucleus. The cytosolic level of IKB decreased following treatment with LPS alone, and zerumbone inhibited the reduction in IkB level. The level of $\mathrm{p} 65$, an NF- $\kappa \mathrm{B}$ component, was increased by approximately twofold in the LPS-treated group compared with that in the control group. Zerumbone treatment reduced the level of p65 to approximately the level in the control group (Fig. 4a-c). Zerumbone inhibited LPS-induced expression of genes related to inflammation by inhibiting the translocation of $\mathrm{NK}-\mathrm{KB}$ to the nucleus.

\section{Discussion}

In this study, we hypothesized that neuroprotection can be achieved by inhibiting microglial activation using zerumbone. To this end, we determined the anti-inflammatory effect of zerumbone on lipopolysaccharideinduced activation of BV-2 microglial cells and elucidated the underlying mechanism of action. We found that zerumbone suppressed the production of NO and PGE2 as well as the expression of genes related to inflammation induced by LPS.

Following the discovery of the association between microglial overactivation in the brain and various degenerative diseases including Alzheimer's disease, the suppression of inflammatory responses by inhibiting microglial activation has been accepted as a preventive or therapeutic strategy for brain diseases. Substances that may exhibit anti-inflammatory effects in the brain have thus drawn attention and been studied. Zerumbone has been extensively investigated since the start of the $2000 \mathrm{~s}$

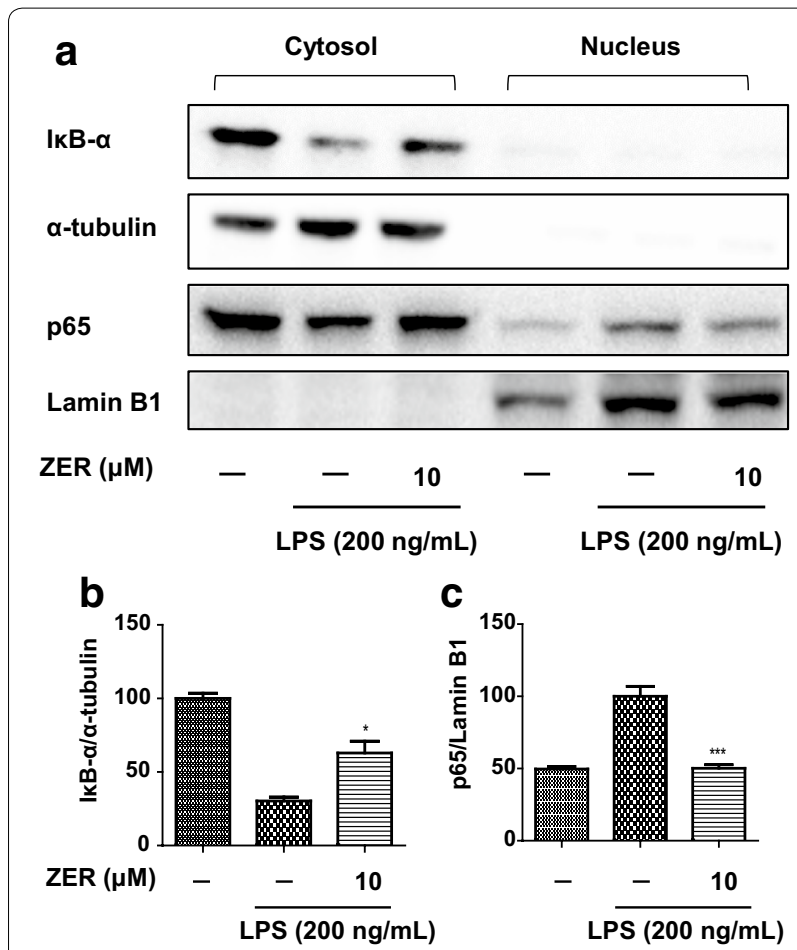

Fig. 4 Effect of zerumbone (10 $\mu \mathrm{M})$ on IKBa degradation in cytosol and translocation of p65, an NF-KB component, to the nucleus in LPS-activated BV-2 cells (a). Normalization of $1 \mathrm{kBa}$ and $\mathrm{p} 65$ protein expression to that of a-tubulin for IKBa and Lamin B1 for p65 (b, c)

owing to its various bioactivities. It has been found to effectively inhibit cancer cell proliferation and migration. This anticancer effect of zerumbone has been reported to be associated with anti-inflammatory responses; zerumbone was found to effectively inhibit cytotoxicity caused by excessive inflammatory responses.

Zerumbone inhibited the expression of iNOS and COX-2 involved in the production of $\mathrm{NO}$ and $\mathrm{PGE}_{2}$. $\mathrm{NO}$ is a major cytotoxic substance and hallmark of activated BV-2 cells. It inhibited iNOS expression even at a low concentration of $1 \mu \mathrm{M}$, indicating that zerumbone plays a role in the signal transduction pathways involved in LPS-induced gene expression. MAPK phosphorylation and NK- $\mathrm{kB}$ activation are major LPS-activated signal transduction pathways in microglial cells. MAPKs are a group of signal-transducing proteins and major target molecules that inhibit LPS-induced inflammatory reactions [24]. NF- $\kappa B$ is a transcription factor that mediates inflammatory responses, and it is involved in the expression of many inflammation-related genes [25]. Many substances that exert anti-inflammatory effects in microglia inhibit the activation of MAPK and NF-kB [26-28]. We examined whether zerumbone inhibited the production of $\mathrm{NO}, \mathrm{PGE}_{2}$, and proinflammatory cytokines by 
inhibiting MAPK and NF- $\mathrm{KB}$ activation and found that zerumbone inhibits the phosphorylation of $\mathrm{p}-38$ and JNK. It significantly inhibited JNK phosphorylation and inhibited NK- $\mathrm{KB}$ translocation to the nucleus. The inhibition of MAPK phosphorylation and NK- $\mathrm{KB}$ activation by zerumbone in macrophages has been reported. Zerumbone inhibited NK- $\mathrm{KB}$ phosphorylation in carbon tetrachloride-treated mouse liver tissues and LPS-treated Raw 264.7 cells [29]. It also inhibited Bacteroides fragilis toxininduced phosphorylation and degradation of ІкB and the translocation of NK- $\mathrm{KB}$ to the nucleus in colonic epithelial cells (HT29/C1) [30]. Our results support the above findings on the effects of zerumbone. Taken together, these results indicate that zerumbone can inhibit microglial activation. In a recent study by $\mathrm{Li}$ et al, zerumbone inhibited the production of $\mathrm{NO}$ and pro-inflammatory cytokines as well as amyloid $\beta$-induced activation in a LPS-treated murine microglia cell line (N9) and primary microglia [31]. Li et al. reported zerumbone to be effective in an APP-PS1 transgenic mouse model of Alzheimer's disease [31]. These results are consistent with our findings.

Based on our results and previous findings, zerumbone treatment may be applied to models of degenerative brain diseases, such as Parkinson's disease, stroke, and multiple sclerosis, which are associated with microglia-mediated inflammation. However, this study had certain limitations, for instance, the therapeutic effect of $Z$. zerumbet and zerumbone against degenerative brain diseases will be investigated in future studies. Additionally, further analytical research is needed to standardize the each compound including zerumbone of ginger for development industrially

\begin{abstract}
Abbreviations
ZER: Zerumbone; AD: Alzheimer's disease; CNS: Central nervous system; MTT: 3-(4,5-Dimethylthiazol-2-yl)-2,5-diphenyltetrazolium bromide; NO: Nitric oxide: iNOS: Inducible nitrite oxide synthase; IL-1 1 : Interleukin 1 beta; TNF-a: Tumor necrosis factor alpha; LPS: Lipopolysaccharide; COX-2: Cyclooxygenase-2; NFKB: Nuclear factor kappa-light-chain-enhancer of activated B cells.
\end{abstract}

\section{Acknowledgements}

This work was supported by Main Research Program (E0164400) of the Korea Food Research Institute (KFRI).

\section{Authors' contributions}

MJG performed the research, MJG, SGH and PL analyzed the data, JH, SGH and $\mathrm{PL}$ designed the research, and $\mathrm{JH}$ and $\mathrm{PL}$ wrote the paper. All authors read and approved the final manuscript.

\section{Funding}

Not applicable.

\section{Availability of data and materials}

All data generated or analyzed during this study are included in this published.

\section{Competing interests}

The authors declare that they have no competing interests.

\section{Author details}

${ }^{1}$ Korea Food Research Institute, 245, Nongsaengmyeong-ro, Jeollabukdo 55365, Republic of Korea. ${ }^{2}$ School of Industrial Bio-pharmaceutical Science, Semyung University, Jecheon, Republic of Korea.

Received: 14 July 2020 Accepted: 8 August 2020

Published online: 15 August 2020

\section{References}

1. Ueno M, Fujita F, Tanaka T, Nakamura Y, Kikuta J, Ishii M, Yamashita T (2013) Layer $V$ cortical neurons require microglial support for survival during postnatal development. Nat Neurosci 16(5):543-551

2. Paolicelli RC, Bolasco G, Pagani F, Maggi L, Scianni M, Panzanelli P, Giustetto M, Ferreira TA, Guiducci E, Dumas L, Ragozzino D, Gross CT (2011) Synaptic pruning by microglia is necessary for normal brain development. Science 333(6048):1456-1458

3. Witting A, Muller P, Herrmann A, Kettenmann H, Nolte C (2000) Phagocytic clearance of apoptotic neurons by microglia/brain macrophages in vitro: involvement of lectin-, integrin-, phosphatidylserine-mediated recognition. J Neurochem 75(3):1060-1070

4. Takahashi K, Rochford CDP, Neumann H (2005) Clearance of apoptotic neurons without inflammation by microglial triggering receptor expressed on myeloid cells-2. J Exp Med 201(4):647-657

5. Yang Y, Le W (2016) Differential roles of M1 and M2 microglia in neurodegenerative disease. Mol Neurobiol 53(2):1181-1194

6. Perry VH, Nicoll JA, Holmes C (2010) Microglia in neurodegenerative disease. Nat Rev Neurol 6(4):193-201

7. Hansen DV, Hanson JE, Sheng M (2018) Microglia in Alzheimer's disease. J Cell Biol 217(2):459-472

8. Xiong XY, Liu L, Yang QW (2016) Functions and mechanisms of microglia/ macrophages in neuroinflammation and neurogenesis after stroke. Prog Neurobiol 142:23-44

9. Han Q, Yuan Q, Meng X, Huo J, Bao Y, Xie G (2017) 6-Shogaol attenuates LPS-induced inflammation in BV2 microglia cells by activating PPAR- $\gamma$. Oncotarget 8(26):42001-42006

10. Spagnuolo C, Moccia S, Russo GL (2018) Anti-inflammatory effects of flavonoids in neurodegenerative disorders. Eur J Med Chem 153:105-115

11. Zhang J, Zheng Y, Luo Y, Du Yu, Zhang X, Fu J (2019) Curcumin inhibits LPS-induced neuroinflammation by promoting microglial M2 polarization via TREM2/TLR4/ NF-KB pathways in BV2 cells. Mol Immunol 116:29-37

12. Kalantari K, Moniri M, Moghaddam AB, Rahim RA, Ariff AB, Izadiyan Z, Mohamad R (2017) A review of the biomedical applications of zerumbone and the techniques for its extraction from ginger rhizomes. Molecules 22(10):1645

13. Rahman HS, Rasedee A, Yeap SK, Othman HH, Chartrand MS, Namvar F, Abdul AB, How CW (2014) Biomedical properties of a natural dietary plant metabolite, zerumbone, in cancer therapy and chemoprevention trials. Biomed Res Int 2014:920742

14. Girisa S, Shabnam B, Monisha J, Fan L, Halim CE, Arfuso F, Ahn KS, Sethi G, Kunnumakkara AB (2019) Potential of zerumbone as an anti-cancer agent. Molecules 24(4):734

15. Takada Y, Murakami A, Aggarwal BB (2005) Zerumbone abolishes NF-KB and $\mathrm{IKBa}$ activation leading to suppression of antiapoptotic and metastatic gene expression, upregulation of apoptosis, and downregulation of invasion. Oncogene 24:6957-6969

16. Singh SP, Nongalleima $K$, Singh NI, Doley P, Singh CB, Singh TR, Sahoo D (2018) Zerumbone reduces proliferation of HCT116 colon cancer cells by inhibition of TNF-alpha. Sci Rep 8(1):4090

17. Haque A, Jantan I, Harikrishnan H (2018) Zerumbone suppresses the activation of inflammatory mediators in LPS-stimulated U937 macrophages through MyD88-dependent NF-KB/MAPK/PI3K-Akt signaling pathways. Int Immunopharmacol 55:312-322

18. Haque A, Jantan I, Harikrishnan H, Ghazalee (2019) Standardized extract of Zingiber zerumbet suppresses LPS-induced pro-inflammatory responses through NF-KB, MAPK and PI3K-Akt signaling pathways in U937 macrophages. Phytomedicine 54:195-205 
19. Chien TY, Huang SKH, Lee CJ, Tsai PW, Wang CC (2016) Antinociceptive and anti-inflammatory effects of zerumbone against mono-iodoacetateinduced arthritis. Int J Mol Sci 17(2):249

20. Ho YC, Lee SS, Yang ML, Huang-Liu R, Lee CY, Li YC, Kuan YH (2017) Zerumbone reduced the inflammatory response of acute lung injury in endotoxin-treated mice via Akt-NFkB pathway. Chem Biol Interact 271:9-14

21. Tzeng TF, Liou SS, Chang CJ, Liu IM (2013) Zerumbone, a tropical ginger sesquiterpene, ameliorates streptozotocin-induced diabetic nephropathy in rats by reducing the hyperglycemia-induced inflammatory response. Nutr Metab (Lond) 10(1):64

22. Hwang J, Youn K, Ji Y, Lee S, Lim G, Lee J, Ho CT, Leem SH, Jun M (2020) Biological and computational studies for dual cholinesterases inhibitory effect of zerumbone. Nutrients 12(5):1215

23. Jafarian $S$, Ling $K H$, Hassan Z, Perimal-Lewis L, Sulaiman MR, Perimal EK (2019) Effect of zerumbone on scopolamine-induced memory impairment and anxiety-like behaviours in rats. Alzheimers Dement (NY) 5:637-643

24. Kaminska B (2005) MAPK signaling pathways as molecular targets for anti-inflammatory therapy-form molecular mechanisms to therapeutic benefits. Biochim Biophys Acta 1754(1-2):253-262

25. Baldwin AS (1996) The NF-KB and IkB proteins: new discoveries and insights. Annu Rev Immunol 14:649-683

26. Xiang B, Xiao C, Shen T, Li T (2018) Anti-inflammatory effects of anisalcohol on lipopolysaccharide-stimulated BV2 microglia via selective modulation of microglia polarization and down-regulation of NF-kB p65 and JNK activation. Mol Immunol 95:39-46

27. Youssef M, Ibrahim A, Akashi K, Hossain MS (2019) PUFA-plasmalogens attenuates the LPS-induced nitric oxide production by inhibiting the NF-kB, p38 MAPK and JNK pathways in microglial cells. Neuroscience 397:18-30

28. Yu X, Zhang F, Shi J (2019) Effect of sevoflurane treatment on microglia activation, NF-KB and MAPK activities. Immunobiology 224(5):638-644

29. Wang M, Niu J, Ou L, Deng B, Wang Y, Li S (2019) Zerumbone protects against carbon tetrachloride(CCl4)-induced acute liver injury in mice via inhibiting oxidative stress and the inflammatory response: involving the TLR4/NF-kB/COX-2 pathway. Molecules 24(10):1964

30. Hwang S, Jo M, Hong J, Park C, Lee C, Yun M, Rhee K (2019) Zerumbone suppresses enterotoxigenic Bacteroides fragilis infection-induced colonic inflammation through inhibition of NF-KB. Int J Mol Sci 20(18):4560

31. Li L, Wu XH, Zhao XJ, Xu L, Pan CL, Zhang ZY (2020) Zerumbone ameliorates behavioral impairments and neuropathology in transgenic APP/PS1 mice by suppressing MAPK signaling. J Neuroinflamm 17(1):61

\section{Publisher's Note}

Springer Nature remains neutral with regard to jurisdictional claims in published maps and institutional affiliations.

\section{Submit your manuscript to a SpringerOpen ${ }^{\odot}$ journal and benefit from:}

- Convenient online submission

- Rigorous peer review

- Open access: articles freely available online

- High visibility within the field

- Retaining the copyright to your article

Submit your next manuscript at $\mathbf{s p r i n g e r o p e n . c o m ~}$ 